\title{
Therapeutic Drug Monitoring in Fungal Infections: the Dawn of Proactive Monitoring
}

\author{
Joan Antoni Schoenenberger-Arnaiz ${ }^{1,}{ }^{*}$, Ana Aragones-Eroles ${ }^{2}$, Pilar Taberner-Bonastre ${ }^{1}$ and Arturo Morales-Por- \\ tillo ${ }^{1}$ \\ 1 Pharmacy Service. Hospital Universitari Arnau de Vilanova; jas.lleida.ics@gencat.cat; ptaber- \\ ner.lleida.ics@gencat.cat; amoralesp.lleida.ics@gencat.cat \\ 2 Pharmacokinetic laboratory. Institut de Recerca Biomedica de LLeida; anaragones@gmail.com \\ * Correspondence: jas.lleida.ics@gencat.cat; Tel.: +34973705220
}

\begin{abstract}
Therapeutic Drug Monitoring (TDM) is potentially a useful tool that can be employed to increase the efficacy and decrease the toxicity of antifungal drugs. The aim of this narrative review is to provide an overview of the current use of TDM in clinical practice, and to present the evidence available regarding its use in proactive clinical settings for preventing and managing treatment failure. This review also presents the existing evidence regarding the association of various clinical outcomes with specific thresholds of drug concentrations in everyday practice. Articles concerning the use of TDM of triazoles in the treatment of fungal infections were retrieved through an electronic search using PubMed. In clinical practice, TDM has an increasingly important role in the management of antifungal drugs as a consequence of the improvement in the knowledge of the pharmacokinetics and pharmacodynamics of these drugs. The currently available evidence shows a direct exposure-response relationship for triazoles, though the PK/PD profile is unpredictable. Current guidelines and treatment consensus statements recommend the proactive TDM of voriconazole, posaconazole, and itraconazole to optimize dosage regimens and improve outcomes for adult and pediatric patients.
\end{abstract}

Keywords: therapeutic drug monitoring; proactive; antifungal drugs

\section{Introduction}

Serious fungal infections remain a major challenge in hospitals. Invasive fungal disease is one of the leading causes of morbidity and mortality in immunodeficient patients such as critical patients, newborns, solid organ recipients, cancer patients, and AIDS patients [1-5]. In recent years, there have been changes in the evolution, prognosis, diagnosis, and treatment of fungal diseases [6]. Fungal infections are difficult to diagnose in many patients, as they are rarely detected in blood cultures or aseptic regions. Because the population of critically ill and immunocompromised patients is increasing, the incidence of fungal infections shows a parallel increasing trend [6].

Many studies have shown that the use of antibiotics-especially broad-spectrum antibiotics-is a major risk factor for the development of systemic fungal infections [7]. In recent years, the incidence of Candida infections has increased dramatically, accounting for $80 \%$ of fungal infections [8]. C. albicans is the most prevalent species, but there is an increase in infections caused by other Candida species resistant to different antifungals. The frequency of fungal infections by Aspergillus or other fungi-which account for $20 \%$ of all fungal infections-has also increased [9]. Opportunistic fungi similar to yeasts and microorganisms such as Zygomycetes, Fusarium spp., and Scedosporium spp., appear increasingly in the aforementioned groups of patients. The mortality of systemic fungal infections is high, at $25 \%$ to $60 \%$, and depends on the factors such as the characteristics of the patients and type of fungus [7]. These infections greatly prolong hospital stay with an 
added iatrogenic risk, including the development of resistance or the selection of yeast species resistant to azole antifungals.

It should be noted that in recent years, risk factors for the development of these complications have been identified, which allows the prophylactic use of antifungals in patients at risk [10].

As few new antifungal drugs are in development, it is necessary to explore novel ways of handling the available drugs to increase their effectiveness and safety. To this end, knowledge of the pharmacokinetic (PK) and pharmacodynamic (PD) behavior of the currently available antifungal drugs is fundamentally important [11]. Therapeutic drug monitoring (TDM) could be a useful tool for increasing the effectiveness and decreasing the toxicity of antifungals $[11,12,13]$. However, not all hospitals can perform TDM of drugs that require a relatively rapid response and those that rely on analytical techniques that are not commonly available in conventional clinical laboratories (high-performance liquid chromatography (HPLC)-ultraviolet (UV) and liquid chromatography-mass spectrometry (LC-MS)).

This review article summarizes the latest evidence regarding the use of TDM of antifungals in hospital settings, in addition to its limitations and how it is currently being used in clinical practice. This review focuses specifically on the triazole drug class and we believe that this approach is a needed novelty to improve antifungal stewardship programs.

\section{Background of TDM}

TDM involves the measurement of the serum concentrations of a drug; it is performed to help maintain an adequate dose that would ensure drug efficacy and avoid drug toxicity [14]. Currently, clinical pharmacokinetics occupies a prominent place in pharmacological therapy. The factors that have contributed most to the clinical incorporation of TDM include the elucidation of its theoretical and practical aspects, the wide availability of analytical methods for selected drugs and easy access to computer tools [15]. Medications used in special physiological circumstances such as pregnancy, lactation, old age, and liver or kidney disease require a differentiated therapeutic approach because of the pharmacokinetic and pharmacodynamic changes that occur in these situations [15].

TDM has been reserved for the management of drugs with a narrow therapeutic margin such as digoxin, aminoglycoside antibiotics, vancomycin, anticonvulsants, and immunosuppressants. However, interest in the TDM of other drugs such as beta-lactam antibiotics when used in critically ill patients has recently become widespread [16]. Pharmacokinetic/pharmacodynamic (PK/PD) modeling applied to these anti-infectives is also of interest for antifungals, although it has been explored less frequently. PK/PD modeling links dose-concentration relationships (PK) and concentration-effect relationships (PD), thereby facilitating the description and prediction of the time course of drug effects resulting from a certain dosing regimen [17].

\section{The role of PK/PD determination in antifungal therapy management}

In the management of antifungal therapy, we must select the PK/PD measure (index) most closely linked to efficacy [18]. For anti-infectives, three PK/PD indices are used to describe the relationship among PK, minimum inhibitory concentration (MIC), and drug effect: peak drug concentrations in relation to the MIC (Cmax/MIC), the area under the drug concentration curve in relation to MIC (AUC/MIC), and the time (expressed as a percentage of the dosing interval) at which that drug concentrations exceed the MIC $(\% \mathrm{~T}>\mathrm{MIC})$.

The identification and validation of the PK/PD index that can be applied to all antifungal drug classes are crucial for predictive analysis in clinical practice. For a given $\mathrm{PK} / \mathrm{PD}$ index, the Monte Carlo simulation method is the most robust method for 
optimizing the dosing regimen design and identifying the MIC ceiling (highest MIC) for which the PD target can be achieved [18]. These simulations lead to the establishment of the preferred PK/PD index for each antifungal drug class (Table 1).

Table 1. PK/PD index by antifungal drug class (modified from Lepak et al, [18])

\begin{tabular}{|l|c|l|l|}
\hline Drug class & $\begin{array}{l}\text { Concentration- } \\
\text { dependent action }\end{array}$ & $\begin{array}{l}\text { Prolonged post-antifungal effect } \\
\text { (PAFE) }\end{array}$ & $\begin{array}{l}\text { PK/PD index predictive of } \\
\text { efficacy }\end{array}$ \\
\hline Polyene & Yes & Yes & Cmax/MIC \\
\hline Azoles & No & Yes & AUC/MIC \\
\hline Echinocandins & Yes & Yes & AUC/MIC \\
\hline
\end{tabular}

MIC, minimal inhibitory concentration; AUC, area under the curve timeconcentration

The most studied drugs with reference to establishing a PK/PD index pertain to the azole class (fluconazole, voriconazole, itraconazole, and posaconazole). However, data are scarce for the most recently developed antifungal class, the echinocandins (caspofungin, micafungin, and anidulafungin). Furthermore, the optimal target for a given PK/PD index can vary among different groups of patients, as in the case of beta-lactam antibiotics. Thus, population-based PK/PD index targets are required [19].

\section{PK and the PK/PD index for triazoles}

Triazole antifungals inhibit the synthesis of ergosterol and other sterols, which are key components of the fungal membrane. Triazoles block the fungal cytochrome P450 (CYP450)-dependent enzyme 14-lanosterol demethylase, which is required for the conversion of lanosterol into ergosterol. This causes an accumulation of 14-methyl sterols and likely affects the function of membrane-bound enzyme systems, further altering the proximity of the acyl chains of phospholipids and resulting in decreased fungal growth. Compared to fluconazole, voriconazole is a more powerful inhibitor of fungal CYP450 [20]. These drugs also inhibit the subsequent steps of the ergosterol synthetic pathway. The ergosterol synthetic pathway and the cytochrome P450 system are also functional in the host cells. This is why these drugs present liver toxicity, which is sometimes severe. However, the new derivatives of these drugs have a better safety profile due to increased selectivity for fungal enzymes.

The nonlinear pharmacokinetics of azoles result in an increase in plasma concentrations of the drug as treatment progresses. This includes an increase in the elimination halflife as a consequence of the inhibition of the activity of the enzymes that metabolize the drug. Therefore, the beneficial and adverse effects that depend directly on the concentrations of the drugs may be more evident over time [21]. The PK properties of these antifungal drugs vary depending on the patient's clinical situation, and this may lead to unpredictable plasma drug concentrations, especially in critically ill patients [22].

For triazoles, the absence of concentration-dependent action together with a prolonged post-antifungal effect (PAFE) suggests that the PD/PD index most closely associated with efficacy is AUC/MIC. Initial studies of five triazoles have consistently used a free-drug AUC/MIC of 25-50 as the PD target for a treatment outcome (defined as a 50\% 
maximal effect) against Candida species [18]. A PD target measure in Aspergillus animal models shows that similar to that for Candida, there is a very strong relationship between treatment efficacy and the PD index AUC/MIC. The numerical value of the PK/PD index expresses the amount of drug required for the intended effect.

\subsection{Voriconazole}

Voriconazole has nonlinear pharmacokinetics, possibly because of its saturable metabolism and systemic clearance [23]. The drug has an oral bioavailability of $95 \%$; the peak serum concentration is reached after 1-2 $\mathrm{h}$ if taken with a high-fat meal, and does not decrease with the co-administration of cimetidine, omeprazole, or other inhibitors of gastric secretion ( $\mathrm{pH}$ changes do not affect its absorption) [23]. The steady-state volume of distribution of voriconazole is estimated to be $4.6 \mathrm{~L} / \mathrm{kg}$, and the cerebrospinal fluid concentrations reach $50 \%$ of serum concentrations. Plasma protein binding is estimated to be $58 \%$ $[24,25]$.

Given the MIC distribution of voriconazole against Aspergillus spp. (MIC90 of 1 $\mu \mathrm{g} / \mathrm{mL}$ ), trough concentrations of the drug ranging from 1 to $2 \mu \mathrm{g} / \mathrm{mL}$ have been suggested as optimal outcomes for invasive aspergillosis [26]. However, the 72-h PD target could be higher than 50 using the Clinical Laboratory Standards Institute (CLSI) and European Committee on Antimicrobial Susceptibility Testing (EUCAST) susceptibility breakpoints for voriconazole and Candida albicans. For MICs of 0.06 to $0.125 \mathrm{mg} / \mathrm{L}$, trough levels of 1 to $4 \mathrm{mg} / \mathrm{L}$ would be required to attain the PK/PD target [27].

Voriconazole undergoes hepatic metabolism through the CYP450 enzyme system, and the metabolic products are inactive. While several isoforms of CYP450 are involved in the metabolism of voriconazole, CYP2C19 plays a predominant role [28]. Therefore, changes in CYP2C19 activity or expression have the potential to affect voriconazole plasma levels.

The CYP2C19 gene is highly polymorphic, and more than 30 known variant alleles exist [29]. However, the majority of individuals carry the ${ }^{*} 1,{ }^{*} 2,{ }^{*} 3$, or ${ }^{*} 17$ alleles. CYP2C19*1 is associated with CYP2C19 enzyme that functions normally, while CYP2C19*2 (rs4244285; 19154G>A) and *3 (rs4986893; 17948G>A) are the most common alleles associated with a loss of enzymatic function. CYP2C19*17 is associated with increased enzyme activity, and is incident with frequencies of over $20 \%$ in Europe [30].

Based on the presence of these alleles, individuals can be divided into CYP2C19 ultrarapid metabolizers (UMs), normal metabolizers (NMs), intermediate metabolizers (IMs), and poor metabolizers (PMs). NM individuals are homozygous for the CYP2C19*1 allele, and have a normally functioning enzyme. IMs carry one ${ }^{*} 1$ allele and a loss-offunction allele, resulting in enzymes with reduced function. PMs carry two loss-of-function alleles, resulting in deficient CYP2C19 enzyme activity. UMs carry the *17 allele without a loss-of-function allele $\left({ }^{*} 1 /{ }^{*} 17\right.$ or $\left.{ }^{*} 17 /{ }^{*} 17\right)$, resulting in increased CYP2C19 enzyme activity. The plasma levels of voriconazole decrease with increasing enzyme activity.

\subsection{Posaconazole}

Posaconazole has variable bioavailability depending on its formulation. The first available posaconazole formulation was an oral suspension and was known to cause abortions; its absorption was recognized to be saturable [31]. The suspension had a bioavailability of only $50 \%$ in healthy volunteers, which decreased further by 2.6 points in patients [32]. The administration of a high-fat meal and the concomitant use of drugs such as proton pump inhibitors (PPIs), antacids, H2-receptor functional antagonists, or metoclopramide could reduce the systemic exposure further. As a result of the concerns related to the suspension, a new delayed-released oral tablet formulation was marketed. None of the factors described above were reported to have a clinical impact on the absorption of the delayed-released tablets. Thus, more stable systemic concentrations of posaconazole can be obtained with this formulation [33]; the peak serum concentration is reached after 4-5 h [34,35]. 
Plasma protein binding of the drug is estimated to be $98 \%$, and the drug binds mainly to serum albumin [34]. The volume of distribution is estimated to be $5-25 \mathrm{~L} / \mathrm{kg}$ [Li], and the drug is reported to accumulate preferentially in the lungs, kidney, liver, and heart [31]. Posaconazole is excreted without transformation primarily in the feces, though a small percentage is also eliminated through the renal route. A small percentage of posaconazole is metabolized by CYP450, and 17\% of the drug is glucuronidated by UGT1A4. The halflife of posaconazole is approximately $34 \mathrm{~h}$ [35].

The AUC/MIC target for posaconazole should be 25-100 for Candida [36] and 167-178 for Aspergillus infections [37]. Although the PK/PD index is a measure that links drug exposure and the desired outcome, the trough concentration ( $\mathrm{Cmin}$ ) exhibits a good correlation with this index, and is easier to apply in clinical practice. For prophylaxis, a Cmin higher than $0.7 \mathrm{mg} / \mathrm{L}$ has been described to be necessary; a cut-off of $0.5 \mathrm{mg} / \mathrm{L}$ can be used to define failure in prophylaxis. For treatment, a Cmin of $1.25 \mathrm{mg} / \mathrm{L}$ was first described as necessary, but this recommendation was decreased to $1 \mathrm{mg} / \mathrm{L}$ according to the ESCMIDECMM-ERS guidelines [26]. The sampling schedule must take into account that since posaconazole has a long half-life, the steady-state serum concentration is not reached before the sixth day of treatment (300 mg once daily after a loading dose is administered twice daily on the first day). To date, no concentration-dependent adverse effects have been reported, although the upper limit of the therapeutic range is $3.75 \mathrm{mg} / \mathrm{L}$ [38].

\section{Optimizing antifungal therapies with triazoles}

The individualization of dosing strategies-also called dosing optimization-seeks to maximize treatment efficacy while reducing adverse reactions. It is applied for treatments which are associated with evidence-based improvements in clinical results in general or special populations.

In the treatment of severe bacterial and fungal infections, the application of optimal anti-infective dosing strategies relies on pharmacodynamic analysis. Failure to consider the optimal dose and dosage schedule may jeopardize treatment success, even with early initiation and correct drug choice. Inadequate dosing of antifungals in patients with invasive candidiasis can increase the length of hospital stay and mortality [39].

Because voriconazole is extensively metabolized by the CYP450 system and has a high affinity for the CYP2C19 enzyme, co-administered drugs that share the same metabolic pathway can interfere with the elimination of voriconazole. Blanco-Dorado et al. conducted a study to evaluate the use of voriconazole in daily clinical practice and investigated the potential pharmacokinetic interactions of the drug with concomitant medications [40]. These investigators registered the coadministration of voriconazole and omeprazole in $67.7 \%$ of cases. Omeprazole and other PPIs may increase the plasma concentrations of voriconazole because they inhibit voriconazole metabolism via CYP450 2C19 and 3A4. They found that the simultaneous administration of voriconazole with a drug acting as a CYP450 inhibitor was associated with a higher risk of voriconazole-related toxicity. Unlike voriconazole, posaconazole is only metabolized to a small extent by CYP450. Nevertheless, $20 \%$ of the administered posaconazole is metabolized by UGT enzymes, and thus may be impacted by interactions with drugs that induce UGT enzymes such as phenytoin and rifampin. In addition, posaconazole is a substrate of P-glycoprotein, and its plasma concentrations can be increased by inhibitors of this protein such as verapamil, cyclosporin, and macrolide antibiotics [32].

Cojutti et al. described the effect of co-administration of PPIs and/or steroids with delayed-release posaconazole tablets in patients with hematological malignancies, and reported that the Cmin values of posaconazole were $45 \%$ and $44 \%$ lower, respectively, compared to those without co-administration [42]. Finally, immunosuppression can lead to a decrease in posoconazole bioavailability when the drug is co-administered with metoclopramide, or when diarrhea or mucositis is present. 
The potential for changes in the PK properties of antifungals is clear in patients with important physiological changes that drive PK/PD alterations, such as obese patients and critically ill patients in intensive care units.

Alobaid et al. showed that the standard doses of fluconazole were insufficient to achieve an AUC-time curve for the free unbound drug fraction/MIC ratio of 100 for pathogens with MICs of $\geq 2 \mathrm{mg} / \mathrm{L}$ in critically ill obese patients (BMI $>30 \mathrm{~kg} / \mathrm{m}^{2}$ ) [43]. However, a high-dose voriconazole regimen produced initial supratherapeutic troughs in obese patients, and dose adjustments based on the body weight appears to be a sensible dosing strategy for these patients [44]. Special considerations have to be taken into account with obese patients because of an increased risk of lower posaconazole exposure (34). A recent study described the necessity of increasing the dose to $400 \mathrm{mg} /$ day when the body weight is $120 \mathrm{~kg}$ or more and $500 \mathrm{mg} /$ day when it is $170 \mathrm{~kg}$ or more [32].

Voriconazole and posaconazole are lipophilic compounds; therefore, no alterations in $\mathrm{Vd}$ are expected in critically ill patients. However, increased blood flow can lead to an increase in hepatic metabolism, while myocardial depression can lead to a decrease in hepatic metabolism. Furthermore, liver failure caused by hepatocellular injury will not only result in lower hepatic metabolism and clearance, but will also lead to decreased protein binding linked to a decrease in the production of albumin [22]. The posaconazole clearance and $\mathrm{Vd}$ values in critically ill patients could potentially be two-fold higher than those reported in healthy volunteers (16.8 L/h vs. $6.9 \mathrm{~L} / \mathrm{h}$ and $529 \mathrm{~L}$ vs. $236 \mathrm{~L}$, respectively). The hypoalbuminemia often seen in these patients could account for the increase in the unbound posaconazole fraction, which can then be distributed into tissues and eliminated by clearing organs [32]. However, no studies have documented the influence of hypoalbuminemia on the PK of posaconazole. The AUC and Cmax of the drug in critically ill patients were also lower than those in healthy volunteers [32]. In these patients, the intravenous route of administration is often mandatory, but neither voriconazole nor posaconazole is recommended when $\mathrm{FG}<50 \mathrm{~mL} / \mathrm{min}$ because of the presence of beta-cyclodextrin in the formulation. In such situations, isavuconazole can be administered, because its intravenous formulation is free of the aforementioned solubilizer and no dose adjustment is necessary in patients with renal impairment, including patients with end-stage renal disease [45].

Voriconazole dosage optimization is complex, due to the several factors previously discussed. Additionally, fixed-dose regimens of posaconazole have been shown to result in suboptimal exposure [34]. Therefore, proactive TDM may be a valuable tool for optimizing antifungal therapy with these triazole drugs.

\section{TDM in clinical practice}

Although TDM of systemic antifungal treatments is not universally recommended, there are recommendations for the routine use of TDM in patients receiving voriconazole, itraconazole, and posaconazole [46]. In clinical practice, drug exposure is monitored by measuring blood trough concentrations (Cmin), which serve as surrogate markers of the AUC.

For voriconazole, recent data suggest a Cmin target for TDM between 1 and $6 \mathrm{mg} / \mathrm{L}$ when the drug is used to treat an established invasive infection [46]. Lee et al. recently conducted a systematic review that examined the current knowledge on the impact of TDM on the treatment efficacy and/or toxicity of voriconazole [47]. They only found two randomized clinical trials (RCTs), and both these RCTs studied the relationship between TDM and voriconazole efficacy. In the first study [48], 110 patients were randomized to receive a fixed, standard dosage of voriconazole (non-TDM group) or to receive an adjusted dosage according to the serum trough level measured on the fourth day after treatment initiation (TDM group). The findings of this trial were as follows: (1) the proportion of patients with voriconazole discontinuation due to adverse events was significantly lower in the TDM group than in the non-TDM group (4\% vs. 17\%) and (2) there was a 
significantly higher proportion of complete or partial responses in the TDM group (81\%) than in the non-TDM group (57\%). In the second and prematurely discontinued RCT, only 29 patients were randomized to the TDM or control arms, and a higher success rate was observed in the TDM arm ( $85.7 \%$ vs. $46.7 \%$ control; $\mathrm{P}=0.05)$ [49]. Observational studies have reported significant associations between voriconazole Cmin levels and voriconazole-related AEs; AEs were predominantly related to hepatotoxicity and neurotoxicity [43]. A meta-analysis by Luong et al. found that therapeutic voriconazole serum concentrations (1.0-2.2 $\mathrm{mg} / \mathrm{L})$ were associated with better outcomes, and that patients with supratherapeutic voriconazole serum concentrations $(4.0-6.0 \mathrm{mg} / \mathrm{L})$ experienced increased toxicity [50].

The TDM process of posaconazole is not as extensive as that of voriconazole, probably because it is less frequently used in clinical practice; the TDM process for posaconazole is also controversial. Vaes et al. conducted a prospective study to measure the plasma concentrations of posaconazole in patients prophylactically treated with an oral suspension of the drug, to evaluate the impact of comedications, mucositis, and emesis on drug concentrations [51]. Their study confirmed the high variability of plasma posaconazole concentrations (PPCs) and the significant influence of these factors on posaconazole bioavailability. However, they concluded that the utility of TDM remains to be clarified. In contrast, others have advocated the routine use of TDM when an oral suspension of posaconazole is used $[23,31]$. Regarding the use of intravenous formulations and tablet formulations with improved bioavailability, Bellmann et al. stated that although exposure is probably less variable with these formulations, TDM would be of value in specific populations such as the critically ill patient population [23].

Table 2 summarizes the current recommendations in clinical practice guidelines and position papers. TDM of voriconazole is strongly recommended across all the documents reviewed, and the recommendation is supported by moderate-quality evidence. No significant differences were detected in the sampling schedule or therapeutic range. 
Table 2. Summary of the current recommendations in clinical practice guidelines and position papers

\begin{tabular}{|c|c|c|c|c|}
\hline Guideline/Position paper & Recommendation for TDM & Sampling schedule & Therapeutic range & When to apply TDM \\
\hline $\begin{array}{l}\text { Antimicrobial therapeutic drug monitor- } \\
\text { ing in critically ill adult patients: a Position } \\
\text { Paper } \\
\text { European Society of Intensive Care Medi- } \\
\text { cine (ESICM), European Society of Clinical } \\
\text { Microbiology and Infectious Diseases } \\
\text { (ESCMID), International Association of } \\
\text { Therapeutic Drug Monitoring and Clinical } \\
\text { Toxicology (IATDMCT), and International } \\
\text { Society of Antimicrobial Chemotherapy } \\
\text { (ISAC) [52] }\end{array}$ & $\begin{array}{l}\text { Voriconazole: yes, Cmin monitoring } \\
\text { Posaconazole: neither recommended } \\
\text { nor discouraged; Cmin monitoring } \\
\text { Itraconazole: neither recommend nor } \\
\text { discourage. Cmin monitoring } \\
\text { Isavuconazole: neither recommended } \\
\text { nor discouraged }\end{array}$ & $\begin{array}{l}\text { Voriconazole: one sample just be- } \\
\text { fore the next dosing. Sampling } \\
\text { within 2-5 days post-initiation of } \\
\text { therapy. } \\
\text { Posaconazole: one sample just be- } \\
\text { fore the next dosing. Sampling af- } \\
\text { ter } 7 \text { days of initiation of therapy. } \\
\text { Itraconazole: one sample just be- } \\
\text { fore the next dosing. Sampling } \\
\text { within } 2-5 \text { days post-initiation of } \\
\text { therapy. }\end{array}$ & $\begin{array}{l}\text { Voriconazole: Cmin: } 2-6 \mathrm{mg} / \mathrm{L} \\
\text { (prophylaxis or treatment) } \\
\text { Posaconazole: } C \text { min }>0.5-0.7 \mathrm{mg} / \mathrm{L} \\
\text { (prophylaxis); Cmin }>1 \mathrm{mg} / \mathrm{L} \text { (treat- } \\
\text { ment) } \\
\text { Itraconazole: } C \min >0.5-1 \mathrm{mg} / \mathrm{L}\end{array}$ & $\begin{array}{l}\text { Voriconazole: displays nonlin- } \\
\text { ear PK in adults and exhibits ex- } \\
\text { tensive inter-individual PK vari- } \\
\text { ability in all patient populations }\end{array}$ \\
\hline $\begin{array}{l}\text { Treatment of invasive fungal diseases in } \\
\text { cancer patients- } \\
\text { Revised } 2019 \text { Recommendations of the In- } \\
\text { fectious Diseases Working Party (AGIHO) } \\
\text { of the German Society of Hematology and } \\
\text { Oncology (DGHO) [53] }\end{array}$ & $\begin{array}{l}\text { Voriconazole: recommended (BIIr) } \\
\text { Posaconazole: recommend with oral } \\
\text { suspension and tablets; BIIr for treat- } \\
\text { ment. } \\
\text { Isavuconazole: not generally necessary } \\
\text { (CIII) }\end{array}$ & $\begin{array}{l}\text { Voriconazole: sampling within } 2-5 \\
\text { days post-initiation of therapy and } \\
\text { continued weekly. } \\
\text { Posaconazole: one sample just be- } \\
\text { fore the next dosing; Sampling af- } \\
\text { ter } 7 \text { days of initiation of therapy. }\end{array}$ & $\begin{array}{l}\text { Voriconazole: Cmin: } 2-5 \mathrm{mg} / \mathrm{L} \\
\text { (treatment) } \\
\text { Posaconazole: } \text { Cmin }=700-1830 \\
\mathrm{ng} / \mathrm{mL} \text { (prophylaxis); Cmin= } 800- \\
2100 \mathrm{ng} / \mathrm{mL} \text { (prophylaxis and ther- } \\
\text { apy); Cmin }>1 \mathrm{mg} / \mathrm{L} \text { (therapy) }\end{array}$ & $\begin{array}{l}\text { Voriconazole: all patients } \\
\text { Posaconazole: drug interactions, } \\
\text { fasting condition, increased gas- } \\
\text { tric } \mathrm{pH} \text {, extreme patient weights, } \\
\text { diarrhea. }\end{array}$ \\
\hline $\begin{array}{l}\text { Clinical Practice Guideline for the Man- } \\
\text { agement of Candidiasis: } 2016 \text { Update by } \\
\text { the Infectious Diseases Society of America } \\
\text { [54] }\end{array}$ & $\begin{array}{l}\text { Voriconazole: recommended } \\
\text { Posaconazole: not enough data } \\
\text { Itraconazole: neither recommended nor } \\
\text { discouraged }\end{array}$ & & $\begin{array}{l}\text { Voriconazole: } \mathrm{Cmin}=1-5.5 \mathrm{mg} / \mathrm{L} \\
\text { Itraconazole: Treatment success has } \\
\text { been associated with concentrations } \\
\geq 1 \mathrm{mg} / \mathrm{L} \text { and toxicity with concen- } \\
\text { trations }>5 \mathrm{mg} / \mathrm{L}\end{array}$ & \\
\hline $\begin{array}{l}\text { Diagnosis and management of Aspergillus } \\
\text { diseases: executive summary of the } 2017 \\
\text { ESCMID-ECMM-ERS guideline [26] }\end{array}$ & $\begin{array}{l}\text { Voriconazole: yes, strong in children } \\
\text { (AII) } \\
\text { Posaconazole: yes, for oral suspension; } \\
\text { AII for treatment, CII for prophylaxis } \\
\text { Itraconazole: yes, for the treatment and } \\
\text { prophylaxis of invasive aspergillosis } \\
\text { (AII) }\end{array}$ & $\begin{array}{l}\text { Voriconazole: sampling within } 2-5 \\
\text { days post initiation of therapy, and } \\
\text { continued weekly } \\
\text { Posaconazole: one sample just be- } \\
\text { fore the next dosing. Sampling af- } \\
\text { ter } 5 \text { days of initiation of therapy }\end{array}$ & $\begin{array}{l}\text { Voriconazole: } \mathrm{Cmin}=1-5.5 \mathrm{mg} / \mathrm{L} \text {; If } \\
\text { reduced azole susceptibility (MIC } 2 \\
\mathrm{mg} / \mathrm{mL} \text { ), then Cmin }>2 \mathrm{mg} / \mathrm{L} \text { (AII, } \\
\text { safety and efficacy) } \\
\text { Posaconazole: } \mathrm{Cmin}>1 \mathrm{mg} / \mathrm{L} \\
\text { Itraconazole: } \mathrm{Cmin}=0.5-4 \mathrm{mg} / \mathrm{L} \\
\text { (measured by HPLC) is }\end{array}$ & \\
\hline
\end{tabular}




\begin{tabular}{|c|c|c|c|c|}
\hline Guideline/Position paper & Recommendation for TDM & Sampling schedule & Therapeutic range & When to apply TDM \\
\hline & Isavuconazole: no & & $\begin{array}{l}\text { recommended for prophylaxis (AII } \\
\text { (efficacy), BII (safety)) } \\
\text { Cmin }=1-4 \mathrm{mg} / \mathrm{L} \text { is recommended } \\
\text { during the treatment of IA (AII (effi- } \\
\text { cacy), BII (safety)) }\end{array}$ & \\
\hline $\begin{array}{l}\text { Clinical practice guideline for the manage- } \\
\text { ment of invasive diseases caused by As- } \\
\text { pergillus: } 2018 \text { Update by the } \\
\text { GEMICOMED-SEIMC/REIPI [53] }\end{array}$ & $\begin{array}{l}\text { TDM of antifungal agents is generally } \\
\text { recommended (AII) } \\
\text { TDM for isavuconazole is not currently } \\
\text { recommended (BIII) }\end{array}$ & $\begin{array}{l}\text { First sample (trough sample) for } \\
\text { TDM must be obtained once the } \\
\text { steady state has been reached ( } 3-7 \\
\text { days depending on the antifungal) } \\
\text { (AI) } \\
\text { Repeated at least once per week af- } \\
\text { ter dose stability is achieved (CIII) }\end{array}$ & $\begin{array}{l}\text { Voriconazole: between } 1 \mathrm{mg} / \mathrm{L} \text { and } \\
6 \mathrm{mg} / \mathrm{L} \text { (AII) Posaconazole: trough } \\
\text { levels }>0.7 \mathrm{mg} / \mathrm{L} \text { for prophylaxis } \\
\text { and }>1.0-1.25 \mathrm{mg} / \mathrm{L} \text { for treatment } \\
\text { (AII) } \\
\text { A new target needs to be defined } \\
\text { for new posaconazole formulations } \\
\text { (BIII) } \\
\text { Itraconazole: trough concentration } \\
\text { of } 0.5-1 \mathrm{mg} / \mathrm{L} \text { (measured by HPLC) } \\
\text { is recommended (AII) }\end{array}$ & $\begin{array}{l}\text { Where non-compliance, non-lin- } \\
\text { ear pharmacokinetics, inade- } \\
\text { quate absorption, a narrow ther- } \\
\text { apeutic window, suspected drug } \\
\text { interaction, or unexpected tox- } \\
\text { icity are encountered (AI) }\end{array}$ \\
\hline
\end{tabular}

TDM, therapeutic drug monitoring; PK, pharmacokinetics; MIC, minimum inhibitory concentration; HPLC, high-performance liquid chromatography 


\section{Practical aspects- best way to apply TDM}

Currently, antimicrobial stewardship (AMS) is recognized as a major tool to improve outcomes in infectious diseases, and the principles of AMS guidelines also apply to the stewarding of antifungal agents [57]. In this review of the core elements of the TDM approach, it is recommended that the management and interpretation of TDM of antifungals are essential activities of antifungal stewardship (AFS). These activities are usually carried out by a clinical pharmacist specializing in infectious diseases. The TDM-guided dosage determination of triazoles is challenging in drugs with nonlinear PK such as voriconazole. Therefore, pharmacists should have access to PK-related software to manage pharmacokinetically complex antifungal agents. Pmetrics-which can be obtained at www.lapk.org is a free software-and is extremely flexible. It also has the capacity to employ nonparametric PK/PD models [58].

Once triazole therapy is initiated, the results of the TDM are to be reported in a timely manner to the AFS team and clinicians, so that personalized dose adaptation can be applied. Ideally, in centers routinely managing patients with invasive fungal disease, inhouse TDM should be available. McCready et al. showed that in-house TDM capabilities reduce the time to drug concentration results and time to achieve therapeutic drug concentrations, when compared with the use of an outside reference laboratory. In the abovementioned study subtherapeutic drug concentrations were associated with increased mortality [59].

Sampling times in relation to the real drug dose are of paramount importance. If accurate time information for blood samples is missing or incorrectly registered, or dosage information is misleading, then it is possible that inappropriate dosing guidelines may be issued [60]. This will eventually result in undesirable treatment outcomes such as lack of efficacy or increased toxicity. Sampling time errors are possibly responsible for the majority of errors in interpreting PK data. The selection of sampling times must allow for the determination of the maximum amount of PK and clinical information [61].

\section{Limitations of TDM}

In clinical practice, RCTs are considered as the gold standard for providing evidence for causal relationships and to support changes. The majority of data available regarding TDM have been based mainly on prospective and retrospective observational studies, or post-HOC analyses. In addition to the timing and frequency of TDM, other issues around TDM include difficulties in interpreting the results due to delays in obtaining the results, and obstacles to the timely implementation of required dosage changes [61].

In some circumstances, the utility of TDM for antifungals can be limited by other factors. For example, TDM is highly recommended for the individualization of dosage in transplant patients on immunosuppressants. Although TDM might be a new option for the administration of midostaurin and posaconazole, the lack of prospective studies that specifically assess the interactions of antifungal prophylaxis and midostaurin jeopardizes this approach. Furthermore, in this case, the PK approach requires the determination of the plasma concentrations of midostarurin metabolites, but the corresponding TDM method is not yet available [62].

TDM application relies on the use of sophisticated laboratory techniques, requires the involvement of highly specialized staff, and is time consuming. This implies the need for financial resources, which can further limit the usefulness of TDM. New antifungal agents such as isavuconazole with enhanced PK or safety profiles and more predictable PK properties will reduce the need for the routine use of TDM in the management of fungal infections [63].

\section{Conclusion}


In clinical practice, TDM has an increasing role in the management of antifungal drugs such as voriconazole, as a consequence of the improvement in the knowledge of the PK and PD of these drugs. There is evidence that shows a direct exposure-response relationship for this and other triazoles depending on the fungal infection; an unpredictable PK/PD profile and a narrow therapeutic index have been reported. The current guidelines and treatment consensus statements recommend proactive TDM of voriconazole, posaconazole, and itraconazole to optimize dosage regimens and improve outcomes for adult and pediatric patients, especially those with emerging resistant pathogens. However, preliminary data do not support the routine use of TDM for novel agents such as isavuconazole. Limitations in obtaining results in a timely manner and constraints in economic resources could jeopardize its utility.

Author Contributions: All authors contributed equally to this paper with regards to the conception and structure of the paper in addition to the literature review, drafting and revision with unanimous approval of the final version.

Funding: This research received no external funding

Institutional Review Board Statement: not applicable.

Acknowledgments: We would like to thank Editage (www.editage.com) for English language editing.

Conflicts of Interest: The authors declare no conflict of interest.

\section{References}

1.- Limper AH, Adenis A, Le T, Harrison TS. Fungal infections in HIV/AIDS. Lancet Infect Dis. 2017 Nov;17(11):e334e343. doi: 10.1016/S1473-3099(17)30303-1. Epub 2017 Jul 31. PMID: 28774701.

2.- Kennedy CC, Razonable RR. Fungal Infections After Lung Transplantation. Clin Chest Med. 2017 Sep;38(3):511-520. doi: 10.1016/j.ccm.2017.04.011. Epub 2017 May 20. PMID: 28797492; PMCID: PMC5657246.

3.- Righi E. Management of bacterial and fungal infections in end stage liver disease and liver transplantation: Current options and future directions. World J Gastroenterol. 2018 Oct 14;24(38):4311-4329. doi: 10.3748/wjg.v24.i38.4311. PMID: 30344417; PMCID: PMC6189843.

4.- Metaxa V, Bauer P, Povoa P et al.. Diagnosis of severe respiratory infections in immunocompromised patients. Intensive Care Med. 2020 ;46(2):298-314. doi: 10.1007/s00134-019-05906-5. Epub 2020 Feb 7. PMID: 32034433; PMCID: PMC7080052.

5.- Omrani AS, Almaghrabi RS. Complications of hematopoietic stem transplantation: Fungal infections. Hematol Oncol Stem Cell Ther. 2017 Dec;10(4):239-244. doi: 10.1016/j.hemonc.2017.05.013. Epub 2017 Jun 13. PMID: 28636889.

6.- Eades CP, Armstrong-James DPH. Invasive fungal infections in the immunocompromised host: Mechanistic insights 
in an era of changing immunotherapeutics. Med Mycol. 2019 Jun 1;57(Supplement_3):S307-S317. doi: 10.1093/mmy/myy136. PMID: 31292657.

7.- Poissy J, Damonti L, Bignon A et al. FUNGINOS; Allfun French Study Groups. Risk factors for candidemia: a prospective matched case-control study. Crit Care. 2020 ;24(1):109. doi: 10.1186/s13054-020-2766-1. PMID: 32188500; PMCID: PMC7081522.

8.- Gonzalez-Lara MF, Ostrosky-Zeichner L. Invasive Candidiasis. Semin Respir Crit Care Med. 2020 ;41(1):3-12. doi: 10.1055/s-0040-1701215. Epub 2020 Jan 30. PMID: 32000280.

9.- López-Cortés L, Garcia-Vidal C, Ayats J, et al. Revista Iberoamericana de Micología. Rev Iberoam Micol. $2012 ; 29(3): 23-34$

10.- Perez J, Guna R, Orta N, Gimeno C. Nuevos Azoles : Voriconazol. Control Calid SEIMC. Published online 2003:110. Available at https://seimc.org/contenidos/ccs/revisionestematicas/micologia/Neoazoles.pdf

11.- Universitario H, Dureta S. Monitorización de los niveles plasm á ticos de antifúngicos. Published online 2010:1-21. Available

https://www.elcomprimido.com/FARHSD/CursoAntimicrobianos2010/Monitorizacion_Antifungicos_Bernardino_ Barcelo_Feb2010.pdf

12.- Cendejas-Bueno E, Cuenca-Estrella M, Gómez-López A. Appeaindicaciones clínicas de la monitorización de azoles de uso sistémico. hacia la optimización del tratamiento de la infección fúngica. Rev Esp Quimioter. 2014;27(1):1-16.

13.- Schoenenberger JA, Aragones AM, Cano SM, et al. The advantages of therapeutic drug monitoring in patients receiving antiretroviral treatment and experiencing medication-related problems. Ther Drug Monit. 2013;35(1):71-77. doi:10.1097/FTD.0b013e3182791f8c

14.- Leslie Escobar QF. Monitorización Terapéutica De Fármacos Y Aspectos Prácticos De Farmacocinética. Rev Médica Clínica Las Condes. 2016;27(5):605-614. doi:10.1016/j.rmclc.2016.09.006

15.- Bauer LA. Clinical Pharmacokinetics and Pharmacodynamics. In: DiPiro JT, Talbert RL, Yee GC, Matzke GR, Wells BG, Posey L. eds. Pharmacotherapy: A Pathophysiologic Approach, 10e. McGraw-Hill; Accessed April 01, 2021. https:/ / accesspharmacy.mhmedical.com/content.aspx?bookid=1861\&sectionid=146077432 
16.- Dhaese S, Van Vooren S, Boelens J al.. Therapeutic drug monitoring of $\beta$-lactam antibiotics in the ICU. Expert Rev Anti Infect Ther. 2020 ;18(11):1155-1164. doi: 10.1080/14787210.2020.1788387. Epub 2020 Jul 5. PMID: 32597263.

17.- Asín-Prieto E, Rodríguez-Gascón A, Isla A. Applications of the pharmacokinetic/pharmacodynamic (PK/PD) analysis of antimicrobial agents. J Infect Chemother. 2015 May;21(5):319-29. doi: 10.1016/j.jiac.2015.02.001. Epub 2015 Feb 12. PMID: 25737147.

18.- Lepak AJ, Andes DR. Antifungal pharmacokinetics and pharmacodynamics. Cold Spring Harb Perspect Med. 2014 Nov 10;5(5):a019653. doi: 10.1101/cshperspect.a019653. PMID: 25384765; PMCID: PMC4448584.

19.- Mohd Sazlly Lim S, Sinnollareddy M, Sime FB. Challenges in Antifungal Therapy in Diabetes Mellitus. J Clin Med. 2020 Sep 6;9(9):2878. doi: 10.3390/jcm9092878. PMID: 32899911; PMCID: PMC7565282.

20.- Theuretzbacher U, Ihle F, Derendorf H. Pharmacokinetic/pharmacodynamic profile of voriconazole. Clin Pharmacokinet. 2006;45(7):649-63. doi: 10.2165/00003088-200645070-00002. PMID: 16802848.

21.- Azanza JR, García-Quetglas E, Sádaba B. Farmacología de los azoles. Rev Iberoam Micol. 2007;24(3):223-227. doi:10.1016/s1130-1406(07)70047-5

22.- Nynke G. L. Jager, Reinier M. van Hest, Jeffrey Lipman et al.. Therapeutic drug monitoring of anti-infective agents in critically ill patients, Expert Review of Clinical Pharmacology 2016, 9:7, 961-979, DOI: 10.1586/17512433.2016.1172209

23.- Bellmann R, Smuszkiewicz P. Pharmacokinetics of antifungal drugs: practical implications for optimized treatment of patients. Infection. 2017 Dec; 45(6):737-779. doi: 10.1007/s15010-017-1042-z. Epub 2017 Jul 12. PMID: 28702763; PMCID: PMC5696449.

24.- Sienkiewicz BM, Łapiński Ł, Wiela-Hojeńska A. Comparison of clinical pharmacology of voriconazole and posaconazole. Contemp Oncol (Pozn). 2016;20(5):365-373. doi: 10.5114/wo.2016.64594. Epub 2016 Dec 20. PMID: 28373817; PMCID: PMC5371702.

25 VFEND® powder for solution for infusion, film coated tablets and oral suspension. Summary of product characteristics. EMA 2012. Available at https://www.ema.europa.eu/en/documents/product-information/vfend-eparproduct-information en.pdf

26.- Ullmann AJ, Aguado JM, Arikan-Akdagli S et al.. Diagnosis and management of Aspergillus diseases: executive 
summary of the 2017 ESCMID-ECMM-ERS guideline. Clin Microbiol Infect. 2018;24(Suppl 1):e1-e38. doi: 10.1016/j.cmi.2018.01.002. Epub 2018 Mar 12. PMID: 29544767

27.- Beredaki MI, Georgiou PC, Siopi M et al. Harmonization of Voriconazole CLSI and EUCAST Breakpoints for Candida albicans Using a Validated In Vitro Pharmacokinetic/Pharmacodynamic Model. Antimicrob Agents Chemother. 2020 May 21;64(6):e00170-20. doi: 10.1128/AAC.00170-20.

28.- Norie Murayama, Naoko Imai, Takahisa Nakane et al. Roles of CYP3A4 and CYP2C19 in methyl hydroxylated and N-oxidized metabolite formation from voriconazole, a new anti-fungal agent, in human liver microsomes. Biochemical Pharmacology 2007; 73: 2020-2026..https://doi.org/10.1016/j.bcp.2007.03.012.

29.- Moriyama, B., Obeng, A.O., Barbarino, J. et al. Clinical Pharmacogenetics Implementation Consortium (CPIC) Guidelines for CYP2C19 and Voriconazole Therapy. Clin. Pharmacol. Ther.; 2017; 102: 4551. https://doi.org/10.1002/cpt.583

30.- Scott SA, Sangkuhl K, Shuldiner AR et al. PharmGKB summary: very important pharmacogene information for cytochrome P450, family 2, subfamily C, polypeptide 19. Pharmacogenet Genomics. 2012 ;22(2):159-65. doi: 10.1097/FPC.0b013e32834d4962. PMID: 22027650; PMCID: PMC3349992.

31.- Dolton MJ, Ray JE, Marriott D, McLachlan AJ. Posaconazole exposure-response relationship: evaluating the utility of therapeutic drug monitoring. Antimicrob Agents Chemother. 2012 Jun;56(6):2806-13.

32.- Lu Chen, Elke H. J. Krekels et al. Pharmacokinetics and Pharmacodynamics of Posaconazole. Drugs 2020; 80(7): $671-695$.

33.- Kraft WK, Chang PS, van Iersel MLPS et al. Posaconazole tablet pharmacokinetics: lack of effect of concomitant medications altering gastric $\mathrm{pH}$ and gastric motility in healthy subjects. Antimicrob Agents Chemother. 2014;58(7):40204025

34.- Noxafil@. oral suspension, gastro-resistant tablets and concentrate for solution for infusion Summary of product Characteristics . EMA 2021. Available at https://www.ema.europa.eu/en/documents/productinformation/noxafil-epar-product-information en.pdf

35.- Stott KE, Hope WW. Therapeutic drug monitoring for invasive mould infections and disease: pharmacokinetic and pharmacodynamic considerations. J Antimicrob Chemother. 2017 Mar 1;72(suppl_1):i12-i18. doi: 10.1093/jac/dkx029. 
36.- Mensa J and Soriano A. Guia de Terapéutica Antimicrobiana. Edited by Antares. 2019. ISBN: 978-84-88825-26-1

37.- Chen L, Wang $\mathrm{Y}$, Zhang $\mathrm{T}$ et al. Utility of posaconazole therapeutic drug monitoring and assessment of plasma concentration threshold for effective prophylaxis of invasive fungal infections: a meta-analysis with trial sequential analysis. BMC Infect Dis. 2018;18(1):155.

38.- Dekkers BGJ, Bakker M, van der Elst KCM, et al. Therapeutic Drug Monitoring of Posaconazole: an Update. Curr Fungal Infect Rep. 2016;10(2):51-61. doi:10.1007/s12281-016-0255-4).

39.- Alexander Lepak A, Andes D. Fungal Sepsis: Optimizing Antifungal Therapy in the Critical Care Setting. Crit Care Clin 27 (2011) 123-147. doi:10.1016/j.ccc.2010.11.001

40.- Sara Blanco-Dorado, Cristina Cea-Arestin, Alba González Carballo et al. An observational study of the efficacy and safety of voriconazole in a real-life clinical setting, Journal of Chemotherapy; 2018; DOI: 10.1080/1120009X.2018.1524085

41.- Cojutti PG, Candoni A, Lazzarotto D et al. Co-administration of proton pump inhibitors and/or of steroids may be a risk factor for low trough concentrations of posaconazole delayed-released tablets in adult patients with haematological malignancies. Br J Clin Pharmacol. 2018 ;84(11):2544-2550. doi: 10.1111/bcp.13707. Epub 2018 Aug 19.

42.- Alobaid AS, Wallis SC, Jarrett P et al. Effect of Obesity on the Population Pharmacokinetics of Fluconazole in Critically Ill Patients. Antimicrob Agents Chemother. 2016;60(11):6550-6557. doi: 10.1128/ AAC.01088-16

43.- Patrick G. Richards, Kimberlyn M. Dang, Carol A. Kauffman et al. Therapeutic drug monitoring and use of an adjusted body weight strategy for high-dose voriconazole therapy, Journal of Antimicrobial Chemotherapy; 2017; 72: 1178-1183, https://doi.org/10.1093/jac/dkw550

44.- Cattaneo C, Panzali A, Passi A, et al. Serum posaconazole levels during acute myeloid leukaemia induction therapy: correlations with breakthrough invasive fungal infections. Mycoses. 2015; 58:362-367.

45.- Cresemba ${ }^{\circledR} 200 \mathrm{mg}$ powder for concentrate for solution for infusion Summary of product Characteristics . EMA 2020. Available at https://www.ema.europa.eu/en/documents/product-information/cresemba-epar-productinformation en.pdf

46.- Gómez-López A. Antifungal therapeutic drug monitoring: focus on drugs without a clear recommendation. Clin 
Microbiol Infect. 2020 ;26(11):1481-1487. doi: 10.1016/j.cmi.2020.05.037. Epub 2020 Jun 11. PMID: 32535150.

47.- Lee J, Ng P, Hamandi B et al. Effect of Therapeutic Drug Monitoring and Cytochrome P450 2C19 Genotyping on Clinical Outcomes of Voriconazole: A Systematic Review. Annals of Pharmacotherapy. 2021;55(4):509-529. doi:10.1177/1060028020948174

48.- Park WB, Kim NH, Kim KH et al. The effect of therapeutic drug monitoring on safety and efficacy of voriconazole in invasive fungal infections: a randomized controlled trial. Clin Infect Dis. 2012 Oct;55(8):1080-7. doi: 10.1093/cid/cis599. Epub 2012 Jul 3. PMID: 22761409.

49.- Neofytos D, Ostrander D, Shoham S, et al. Voriconazole therapeutic drug monitoring: results of a prematurely discontinued randomized multicenter trial. Transpl Infect Dis. 2015;17: 831-837. doi:10.1111/tid.12454

50.- Luong ML, Al-Dabbagh M, Groll AH et al. Utility of voriconazole therapeutic drug monitoring: a meta-analysis. J Antimicrob Chemother. 2016 Jul;71(7):1786-99. doi: 10.1093/jac/dkw099. Epub 2016 May 10. PMID: 27165788.

51.- Vaes M, Hites M, Cotton F et al. Therapeutic drug monitoring of posaconazole in patients with acute myeloid leukemia or myelodysplastic syndrome. Antimicrob Agents Chemother. 2012 ;56(12):6298-303. doi: 10.1128/AAC.01177-12. Epub 2012 Oct 1. PMID: 23027198; PMCID: PMC3497193.

52.- Abdul-Aziz MH, Alffenaar JC, Bassetti M et al. Infection Section of European Society of Intensive Care Medicine (ESICM); Pharmacokinetic/pharmacodynamic and Critically Ill Patient Study Groups of European Society of Clinical Microbiology and Infectious Diseases (ESCMID); Infectious Diseases Group of International Association of Therapeutic Drug Monitoring and Clinical Toxicology (IATDMCT); Infections in the ICU and Sepsis Working Group of International Society of Antimicrobial Chemotherapy (ISAC). Antimicrobial therapeutic drug monitoring in critically ill adult patients: a Position Paper. Intensive Care Med. 2020 ;46(6):1127-1153. doi: 10.1007/s00134-020-06050-1. Epub 2020 May 7. PMID: 32383061; PMCID: PMC7223855

53.- Ruhnke M, Cornely OA, Schmidt-Hieber M et al. Treatment of invasive fungal diseases in cancer patients - Revised 2019 Recommendations of the Infectious Diseases Working Party (AGIHO) of the German Society of Hematology and Oncology (DGHO). Mycoses. 2020;63(7):653-682. doi: 10.1111/myc.13082.

54.- Garcia-Vidal C, Alastruey-Izquierdo A, Aguilar-Guisado M et al. Executive summary of clinical practice guideline for the management of invasive diseases caused by Aspergillus: 2018 Update by the GEMICOMED-SEIMC/REIPI. 
Enferm Infecc Microbiol Clin. 2019 ;37(8):535-541. English, Spanish. doi: 10.1016/j.eimc.2018.03.018. Epub 2018 Jun 28. PMID: 29960829.

55.- Pappas PG, Kauffman CA, Andes DR et al. Clinical Practice Guideline for the Management of Candidiasis: 2016 Update by the Infectious Diseases Society of America. Clin Infect Dis. $2016 ; 62(4):$ e1-50. doi: 10.1093/cid/civ933. Epub 2015 Dec 16. PMID: 26679628; PMCID: PMC4725385.

56.- Patterson TF, Thompson GR 3rd, Denning DW, Fishman JA, Hadley S, Herbrecht R, Kontoyiannis DP, Marr KA, Morrison VA, Nguyen MH, Segal BH, Steinbach WJ, Stevens DA, Walsh TJ, Wingard JR, Young JA, Bennett JE. Executive Summary: Practice Guidelines for the Diagnosis and Management of Aspergillosis: 2016 Update by the Infectious Diseases Society of America. Clin Infect Dis. 2016 ;63(4):433-42. doi: 10.1093/cid/ciw444. PMID: 27481947; PMCID: PMC4967611.

57.-Johnson MD, Lewis RE, Dodds Ashley ES et al. Core Recommendations for Antifungal Stewardship: A Statement of the Mycoses Study Group Education and Research Consortium. J Infect Dis. 2020 ;222(Suppl 3):S175-S198. doi: 10.1093/infdis/jiaa394. PMID: 32756879; PMCID: PMC7403757.

58.- Jelliffe, Roger. (2015). Re: Is there any open-source Pharmacokinetic software? Retrieved from: https://www.researchgate.net/post/Is_there_any_open_source_Pharmacokinetic_software/551e49ded5a3f25f5d8b4 $5 \mathrm{ba} /$ citation/download.

59.- McCreary EK, Bayless M, Van AP et al. Impact of triazole therapeutic drug monitoring availability and timing. Antimicrob Agents Chemother; 2019; 63:e01245-19. https://doi.org/10.1128/AAC.01245-19.

60.- Ambrose PJ, Nitake M, Kildoo CW. Impact of pharmacist scheduling of blood-sampling times for therapeutic drug monitoring. Am J Hosp Pharm. 1988 ;45(2):380-2. PMID: 3364438

61.- Kang JS, Lee MH. Overview of therapeutic drug monitoring. Korean J Intern Med.2009;24(1):1-10. doi:10.3904/kjim.2009.24.1.1

62.- Stemler J, Koehler P, Maurer C et al.Antifungal prophylaxis and novel drugs in acute myeloid leukemia: the midostaurin and posaconazole dilemma. Ann Hematol. 2020 Jul;99(7):1429-1440. doi: 10.1007/s00277-020-04107-1. Epub 2020 Jun 8. PMID: 32514626; PMCID: PMC7316674.

63.- John J, Loo A, Mazur S et al. Therapeutic drug monitoring of systemic antifungal agents: a pragmatic approach for 
adult and pediatric patients. Expert Opin Drug Metab Toxicol. 2019 ;15(11):881-895. doi: 10.1080/17425255.2019.1671971. Epub 2019 Oct 30. PMID: 31550939. 